\title{
Adjuvant chemotherapy of pT1a and pT1b breast carcinoma: results from the NEMESI study
}

\author{
Stefania Gori ${ }^{1} 13^{*}$, Matteo Clavarezza ${ }^{2}$, Salvatore Siena ${ }^{3}$, Jennifer Foglietta ${ }^{1}$, Emiliana Tarenzi ${ }^{3}$, Monica Giordano ${ }^{4}$, \\ Annamaria Molino ${ }^{5}$, Claudio Graiff ${ }^{6}$, Vittorio Fusco ${ }^{7}$, Oscar Alabiso $^{8}$, Editta Baldini ${ }^{9}$, Teresa Gamucci ${ }^{10}$, \\ Giuseppe Altavilla ${ }^{11}$, Davide Dondi ${ }^{12}$ and Marco Venturini ${ }^{2}$
}

\begin{abstract}
Background: The prognosis of pT1a-pT1b breast cancer (BC) used to be considered very good, with a 10-y RFS of $90 \%$. However, some retrospective studies reported a 10-y RFS of $81 \%-86 \%$ and suggested benefit from adjuvant systemic therapy.

Methods: To evaluate the variables that determined the choice of adjuvant chemotherapy and the type of chemotherapy delivered in pT1a-pT1b BC, we analysed the small tumours enrolled in the NEMESI study.

Results: Out of 1,894 patients with pathological stage I-II BC enrolled in NEMESI, 402 (21.2\%) were pT1a-pT1b. Adjuvant chemotherapy was delivered in 127/402 (31.59\%). Younger age, grading G3, high proliferative index, ER-negative and HER2-positive status were significantly associated with the decision to administer adjuvant chemotherapy. An anthracycline without taxane regimen was administered in $59.1 \%$ of patients, anthracycline with taxane in 24.4\%, a CMF-like regimen in $14.2 \%$ and taxane in $2.4 \%$. Adjuvant chemotherapy was administered in 88.4\% triple-negative and 73.46\% HER2-positive pT1a-pT1b BC. Adjuvant trastuzumab was delivered in 30/49 HER2-positive BC (61.2\%).

Conclusions: Adjuvant chemotherapy was delivered in 31.59\% T1a-pT1b BC treated at 63 Italian oncological centres from January 2008 to June 2008. The choice to deliver chemotherapy was based on biological prognostic factors. Anthracycline-based chemotherapy was administered in $83.5 \%$ patients.
\end{abstract}

Keywords: pT1a and pT1b breast cancer, Adjuvant chemotherapy, Adjuvant hormonal therapy

\section{Background}

Breast cancer is the first cause of tumour-related death in women in Italy [1-5]. Moreover, the incidence of breast cancer has been increasing over the last 15 years in industrialised countries as the result of both Rx-mammographic screening programs [1-5] and advances in breast cancer awareness. The increase in incidence due to mammography screening has been due to the increase in small $\mathrm{T} 1$ cancers $[5,6]$. In Italy, the pT1-pT1b incidence was $9.6 \%$ in 1988-1990 and 21.4\% in 2005-2007 (AIRTUM, data not published; www.registri-tumori.it): these tumours were pN0 in $82 \%-85 \%$ of the cases.

\footnotetext{
* Correspondence: stefania.gori@tin.it

'Oncologia Medica, Ospedale Santa Maria della Misericordia, Azienda Ospedaliera di Perugia, Perugia Italy

${ }^{13}$ Division of Medical Oncology, Ospedale S. Maria della Misericordia, Azienda Ospedaliera Perugia, via Dottori 1, Perugia 06122, Italy

Full list of author information is available at the end of the article
}

The prognosis of these small cancers used to be considered very good, with a relapse-free survival rate at 10 years without adjuvant therapy of 90\% [7-11]. However, some retrospective studies have reported a worse outcome, with $81 \%-86 \%$ of relapse-free survival at 10 years [12-15]. Furthermore, Fisher et al. [16] reporting survival data on 1,259 patients with pT1a-pT1b N0 breast cancer enrolled in 5 randomised NSABP trials, suggested that these patients could have benefited from adjuvant systemic therapy. Given that there is an ongoing debate on the adjuvant treatment of these tumours, we analysed the patients with pT1a-pT1b breast cancer enrolled in the NEMESI study, a retrospective observational study conducted in 2009 at 63 Italian oncological centres. We evaluated the adjuvant systemic treatments delivered, the variables which determined the choice to administer chemotherapy, the type

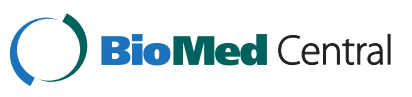


of chemotherapy delivered and compliance with chemotherapy in pT1a-pT1b breast cancers.

\section{Methods}

\section{Study design}

NEMESI is a retrospective observational study conducted at 63 Italian oncological centres. The centres were extracted from a database of 319 oncological centres reported in the census of the Italian Association Medical Oncology (AIOM) [17] and stratified by geographical area (Northern, Central, Southern Italy, including Sicily and Sardinia) and kind of institution (public hospital, university hospital, research institute, private hospital, other), since these factors were considered to have an important impact on compliance with guidelines.

The endpoints of the NEMESI study were: to describe the adjuvant systemic treatments delivered in pathological stage I-II breast cancer, to evaluate the variables which determined the choice of adjuvant chemotherapy and the type of chemotherapy, to evaluate compliance with the treatment administered, and to compare the practice observed in Italian clinical settings with that proposed by international guidelines.

Criteria of eligibility were: women age $\geq 18$ years; histological diagnosis of invasive breast cancer stage I-II (AJCC version VI) [18] who underwent surgery; at least one cycle of adjuvant chemotherapy and/or adjuvant hormonal therapy; availability of the following local staging and biological parameters: pT, pN, grading, estrogen receptor (ER), progesterone receptor (PgR), proliferative index (Ki67 or MIB-1), HER2. Candidates for adjuvant therapy with trastuzumab and/or radiotherapy on residual breast or thoracic wall and/or regional supraclavicular and/or internal breast lymph node stations were also eligible. Exclusion criteria were: neo-adjuvant chemotherapy and/or hormonal therapy, locally advanced and/or metastatic (stage III-IV) breast cancer, and in-situ carcinoma. Data were retrospectively retrieved by each site from the patients' clinical records.

The protocol was reviewed by the independent ethics committee of the coordinating centre and notification of the study was sent to the ethics committees of each participating centre [19]. The protocol complied with the recommendations of the 18th World Health Congress (Helsinki, 1964) [20].

\section{Sample size determination and data collection}

The study aimed at collecting data from the clinical records of not less than 1,300 and not more than 1,500 patients attending at least 50 oncologic centres. These figures correspond to $3.6 \%$ and $4.2 \%$ respectively of the new cases of early stage breast cancer recorded each year in Italy (about 40,000 cases, 90\% of which are early stage), and $12.5 \%$ of the Italian oncologic sites (about 400 throughout Italy).

Each centre was requested to collect, within December 2009 , the data of a minimum of ten and a maximum of 30 consecutive patients with early breast cancer between 1 January 2008 and 30 June 2008; with the only requirement being to collect the data of at least $33 \%$ of the patients undergoing adjuvant chemotherapy. This requirement was mandatory because the primary objective of the study was not to assess how many patients received adjuvant chemotherapy within that period but to identify the biological, staging and demographic parameters that determined: (i) whether adjuvant chemotherapy would be prescribed, and (ii) the type and schedule of chemotherapy selected. To ensure anonymity, the percentage of patients enrolled in the study could not exceed $50 \%$ of the patients attending the centre during the study period. According to the study protocol, central revision of all tissue samples was not done.

The data, collected on an electronic clinical report form, were submitted to automatic checks to assess completeness, correctness and internal coherence. Possible discrepancies or otherwise unreliable data were submitted to the investigator in the form of queries for clarification and/or resolution.

\section{Variables evaluated}

In the NEMESI study patient and tumour characteristics, type of local-regional treatment and adjuvant systemic therapy, and compliance to chemotherapy were evaluated. In this NEMESI sub-study, only the pT1a-pT1b breast cancers were analysed. We evaluated: patient characteristics (age class, menopausal status), stage according to the TNM AJCC version VI classification, bio-pathological characteristics of the primitive tumour (histology, vascular invasion, grading, ER, PgR, HER2, and the proliferative index), type of surgery, adjuvant systemic therapy (chemotherapy, hormonal therapy, trastuzumab, concurrent adjuvant treatment with other experimental drugs), the variables associated with choice of administered adjuvant chemotherapy and compliance to chemotherapy. Moreover, in HER2-positive small tumours the variables associated with choice of administered adjuvant chemotherapy and trastuzamab were analysed.

\section{Statistical methods}

In this survey 402 patients were examined with pT1apT1b breast tumour stage from a total of 1,894 patients enrolled in the NEMESI clinical study. The analysis was performed considering not only the reference population but also various subgroups decided in accordance with different analysis purposes. For most of these groups both descriptive analysis and inferential analysis were performed. As a descriptive analysis, 
continuous variables were summarised using descriptive statistics, including number of subjects: mean, standard deviation, and median, while for categorical variables summaries included counts of subjects and percentages. Pearson's Chi-Square $\left(\chi^{2}\right)$ test was performed in order to evaluate whether the frequency distribution of certain events observed in a sample (for example variables as age, menopausal status, grading, ER status) is consistent with their theoretical distributions. Chi-Square test for Specified Proportions was used to compare, in one way frequency tables, the homogeneity proportion between the general population (pathological stage I-II with the exclusion of pT1a, pT1b, considered as a reference distribution) and the distribution of the same variables in the subgroup of pT1a-pT1b patients. For both tests, the significance level used was equal to $\mathrm{p}=0.05$.

Multivariate logistic regression analysis was performed to assess the relationship between clinical and demographic variables and the type and treatment schedule of adjuvant chemotherapy administered with many covariates: age class, menopausal status, vascular invasion, ECOG performance status, type of surgery, TNM stage, ER, PgR, HER2 status, proliferative index. The logistic model contained only categorical variables. The continuous variables (e.g. proliferative index, ER, PgR, HER2) were categorized in different classes according to international indications.

The selection of variables to include in the model was defined using the stepwise procedure with a significant level of $\mathrm{p}=0.05$ to include variables in the model. In the logistic model the odds ratio estimates and their 95\% confidence limits were also calculated. All statistical analysis was performed using SAS (Statistical Analysis System, SAS Institute Inc., Cary, NC, USA) version 9.1.3 for Windows.

\section{Results}

In the NEMESI study 1,894 patients with pathological stage I-II breast cancer were enrolled by 63 Italian centres. Out of 1,894 cases included in this survey, 402 (21.2\%) were pT1a-pT1b breast cancers. Patient and tumour characteristics are reported in Tables 1 and 2; no considerable relevant differences were observed between pT1a-pT1b breast cancers. Conservative breast surgery and node sentinel biopsy were performed in $86 \%$ and in $79.3 \%$ of pT1a-pT1b tumours, respectively (Table 1 ). The majority of the tumours were pN0 (78.8\%) and showed G1-G2 grading $(80.6 \%)$, absence of vascular invasion (67.5\%), low proliferative index $(71.8 \%)$, hormonal status positive (89.7\%), HER2-status negative (88.12\%) (Table 2). Patients and tumour characteristics of 402 pT1apT1b breast cancers were compared to $1,492 \geq \mathrm{pT} 1 \mathrm{c}$ tumours of NEMESI study (Table 3). The following variables were distributed in a statistically different manner between the groups: menopausal status $(\mathrm{p}=0.015)$, conservative surgery $(\mathrm{p}<0.0001)$, grading $(\mathrm{p}<0.0001)$, proliferative index $(\mathrm{p}<0.0001)$, ER status $(p=0.02)$, hormonal receptor status $(p=0.006)$ and HER2 status $(p=0.009)$. Analysing the different categories of the statistically significant variables, it was observed that in 402 pT1a-pT1b breast cancers compared to other 1,492 cases, there were higher percentages of: postmenopausal patients $(72.8 \%$ vs $68 \% ; \mathrm{p}=0.05)$, tumours that underwent conservative surgery $(86.7 \%$ vs $72.5 \% ; \mathrm{p}=0.005)$ and sentinel node biopsies $(79.4 \%$ vs $60.5 \%$; p $<0.0001)$, tumours with grading G1 (25.1\% vs $8.0 \% ; \mathrm{p}<0.0001)$ and with a low proliferative index (70.6\% vs $47.4 \%$; p $<0.0001)$. In the pT1a-pT1b tumours a lower incidence of prognostic biological factors associated with poor prognosis was observed: ER-negative status $(12.7 \%$ vs $18.5 \%$; $\mathrm{p}=0.01)$, ER and PgR negative status $(11.9 \%$ vs $17.9 \%$; $\mathrm{p}=0.01)$, and HER2-positive status $(12.2 \%$ vs $18.7 \%$; $\mathrm{p}=0.006)$. These small breast cancers $(\leq 1 \mathrm{~cm})$ showed a higher percentage of pN0 (79.4\% vs 56\%; p <0.0001) compared to $1,492 \geq \mathrm{pT} 1 \mathrm{c}$ tumours of the NEMESI study.

Adjuvant chemotherapy was delivered in 127 out of 402 patients $(31.59 \%)$ with pT1a-pT1b breast cancer: in 27 of 82 pT1a tumours (32.9\%) and in 100 of 320 pT1b tumours (31.25\%). Patients and tumour characteristics were analysed to evaluate their influence on the decision to administer or not adjuvant chemotherapy (Table 4). Seventy-two out of 127 patients treated with chemotherapy were pN0 (56.69\%). The multivariate logistic model analysis showed that younger age, grading G3, high proliferative index ( $\geq 30 \% \mathrm{Ki}-67 / \mathrm{Mib} 1)$, ER negative status and HER2-positive status were significantly associated with the decision to administer adjuvant chemotherapy (Table 5).

The multivariate logistic analysis confirmed that ER negative status, high proliferation index, and HER2positive status were significantly associated with the decision to administer adjuvant chemotherapy in patients with pT1b (Table 6), while it could not be performed for pT1a due to the low number of patients $(=27)$. Both analyses excluded the evaluation of axillary lymph node status from the model fit because the distribution of population was unbalanced and it was impossible to estimate the values for the different categories.

We analysed the types of adjuvant chemotherapy administered in 127 patients with pT1a-pT1b tumours. Anthracycline without taxane regimen was administered in $59.1 \%$ of patients, anthracycline with taxane in $24.4 \%$, CMF-like in $14.2 \%$ and taxane without anthracycline in only $2.4 \%$ (Table 7 ). 
Table 1 Patient characteristics and treatment

\begin{tabular}{|c|c|c|c|}
\hline & Total (pT1a and pT1b) & pT1a & pT1b \\
\hline N. of patients & 402 & 82 & 320 \\
\hline \multicolumn{4}{|l|}{ Distribution by age } \\
\hline $18-34$ & $7(1.7 \%)$ & $2(2.4 \%)$ & $5(1.6 \%)$ \\
\hline $35-49$ & $85(21.1 \%)$ & $19(23.2 \%)$ & $66(20.6 \%)$ \\
\hline $50-69$ & $230(57.2 \%)$ & $47(57.3 \%)$ & $183(57.2 \%)$ \\
\hline$\geq 70$ & $80(19.9 \%)$ & $14(17.1 \%)$ & $66(20.6 \%)$ \\
\hline \multicolumn{4}{|l|}{ Menopausal status } \\
\hline Pre- & $101(25.1 \%)$ & $25(30.5 \%)$ & $76(23.8 \%)$ \\
\hline Post- & $293(72.9 \%)$ & $54(65.9 \%)$ & $239(74.6 \%)$ \\
\hline Missing & $8(2.0 \%)$ & $3(3.6 \%)$ & $5(1.6 \%)$ \\
\hline \multicolumn{4}{|l|}{ Surgery: } \\
\hline Breast conservative surgery & $346(86.0 \%)$ & $65(79.3 \%)$ & $281(87.8 \%)$ \\
\hline Mastectomy & $56(13.9 \%)$ & $17(20.7 \%)$ & $39(12.2 \%)$ \\
\hline \multicolumn{4}{|l|}{ Node sentinel biopsy } \\
\hline Yes & $319(79.4 \%)$ & $64(78.0 \%)$ & $255(79.7 \%)$ \\
\hline No & $83(20.6 \%)$ & $18(22.0 \%)$ & $65(20.3 \%)$ \\
\hline \multicolumn{4}{|l|}{ Axillary nodal dissection } \\
\hline Yes & $137(34.1 \%)$ & $31(37.8 \%)$ & $106(33.1 \%)$ \\
\hline No & $265(65.9 \%)$ & $51(62.2 \%)$ & $214(66.9 \%)$ \\
\hline \multicolumn{4}{|l|}{ Radiotherapy } \\
\hline Yes & $317 / 402(78.9 \%)$ & $58 / 82(70.7 \%)$ & $259 / 320(81.0 \%)$ \\
\hline No & $85 / 402(21.1 \%)$ & $24 / 82(29.3 \%)$ & $61 / 320(19.0 \%)$ \\
\hline
\end{tabular}

The small number of patients in the groups treated with different adjuvant chemotherapy regimens did not allow for a statistical evaluation of the patient and tumour characteristics which could have influenced the choice of adjuvant chemotherapy type.

In the few older patients ( $\geq 70$ years) treated with chemotherapy, a CMF-like regimen was administered in $50 \%$; in none of these patients was anthracycline and taxane-based adjuvant therapy chosen. A CMF-like regimen was chosen more frequently in postmenopausal patients (18.1\% vs $9.6 \%)$, in patients with grade G1 tumours ( $22.2 \%$ vs $12.2 \%$ G3) and in patients with cancers having low or moderate proliferative indexes $(14.5 \%$ and $25 \%$ respectively, versus $4.9 \%$ high proliferative index). In pT1b tumours, anthracycline and taxane-based regimen was chosen more frequently than in pT1a breast cancers (28\% in pT1b vs $11.1 \%$ in pT1a) (Table 7 ).

Regarding compliance to adjuvant chemotherapy, it was observed that 105 of 127 patients $(82.67 \%)$ received 4-6 cycles. Delays ( $>7$ days versus planned), were reported in 20 patients $(15.7 \%)$, with a median delay of 7 days (range 7-28). The definitive interruption of chemotherapy occurred in only eight patients: three due to toxicity or severe adverse event, four due to the patient's decision and one due to the investigator's decision.
Hormonal therapy, planned in 351 of the 354 patients with hormonal receptor-positive tumours, was administered in 346 patients $(97.7 \%)$. In pT1a-pT1b breast cancers, tamoxifen with or without LHRH was the hormonal therapy more frequently administered (85.3\%) in premenopausal patients; aromatase inhibitors for 5 years $(67.3 \%)$ was the endocrine treatment more often utilised in the postmenopausal setting, where tamoxifen for 2-3 years followed by aromatase inhibitor for 3-2 years was administered in $17.1 \%$ of patients (Table 8 ).

\section{Adjuvant chemotherapy in triple-negative $\mathrm{pT} 1 \mathrm{a}$ and $\mathrm{pT} 1 \mathrm{~b}$ tumours}

Triple-negative (ER $=0 \%, \operatorname{PgR}=0 \%$, HER2-negative) $\mathrm{pT} 1 \mathrm{a}$ pT1 b tumours were 26 (6.5\%); 2 were pT1a and 24 were pT1b. Adjuvant chemotherapy was administered in $88.4 \%$ of patients (23/26): in 1 of 2 patients with pT1a (50\%) and in 22 of 24 pT1b patients (91.66\%). A CMF-like regimen was administered in 6 patients $(26.1 \%)$, anthracycline without taxane in 11 (47.8\%), anthracycline with taxane in 5 $(21.7 \%)$ and taxane without anthracycline in 1 (4.3\%).

\section{Adjuvant chemotherapy and adjuvant trastuzumab in pT1a and pT1b HER2-positive breast cancers}

Forty-nine pT1a-pT1b tumours were HER2-positive (12.1\%). Adjuvant chemotherapy was delivered to 36 of 
Table 2 Biopathological characteristics

\begin{tabular}{|c|c|c|c|}
\hline & Total (pT1a and pT1b) & pT1a & pT1b \\
\hline N. of patients & 402 & 82 & 320 \\
\hline \multicolumn{4}{|l|}{ Histology } \\
\hline Ductal & $336(83.6 \%)$ & $70(85.4 \%)$ & $266(83.1 \%)$ \\
\hline Lobular & $38(9.5 \%)$ & $7(8.5 \%)$ & $31(9.7 \%)$ \\
\hline Mixed & $5(1.2 \%)$ & $0(0.0 \%)$ & $5(1.6 \%)$ \\
\hline Other & $23(5.7 \%)$ & $5(6.1 \%)$ & $18(5.6 \%)$ \\
\hline \multicolumn{4}{|l|}{ Vascular invasion } \\
\hline Yes & $30(7.5 \%)$ & $3(3.7 \%)$ & $27(8.4 \%)$ \\
\hline No & $267(66.4 \%)$ & $51(62.2 \%)$ & $216(67.5 \%)$ \\
\hline Unknown & $105(26.1 \%)$ & $28(34.1 \%)$ & $77(24.1 \%)$ \\
\hline \multicolumn{4}{|l|}{ Grading } \\
\hline G1 & $101(25.1 \%)$ & $18(22.0 \%)$ & $83(25.9 \%)$ \\
\hline $\mathrm{G} 2$ & $221(55.0 \%)$ & $46(56.1 \%)$ & $175(54.7 \%)$ \\
\hline$\overline{G 3}$ & $72(17.9 \%)$ & $15(18.3 \%)$ & $57(17.8 \%)$ \\
\hline Unknown & $8(2.0 \%)$ & $3(3.7 \%)$ & $5(1.6 \%)$ \\
\hline \multicolumn{4}{|c|}{ Proliferation index (Ki-67/MB1) } \\
\hline $0-18 \%$ & $283(70.5 \%)$ & $53(64.6 \%)$ & $230(71.8 \%)$ \\
\hline $19-29 \%$ & $52(12.9 \%)$ & $17(20.7 \%)$ & $35(10.9 \%)$ \\
\hline$\geq 30 \%$ & $54(13.4 \%)$ & $7(8.5 \%)$ & $47(14.7 \%)$ \\
\hline Unknown & $13(3.2 \%)$ & $5(6.1 \%)$ & $8(2.5 \%)$ \\
\hline \multicolumn{4}{|l|}{ ER status } \\
\hline ER positive ( $\geq 10 \%$ ) & $351(87.3 \%)$ & $65(80.5 \%)$ & $285(89.1 \%)$ \\
\hline ER negative (0-9\%) & $51(12.7 \%)$ & $16(19.5 \%)$ & $35(10.9 \%)$ \\
\hline \multicolumn{4}{|l|}{ PgR status } \\
\hline PgR positive ( $\geq 10 \%)$ & $300(74.6 \%)$ & $54(65.9 \%)$ & $246(76.9 \%)$ \\
\hline PgR negative (0-9\%) & $102(25.4 \%)$ & $28(34.1 \%)$ & $74(23.1 \%)$ \\
\hline \multicolumn{4}{|l|}{ Hormonal status* } \\
\hline ER and/or PgR positive & $354(88.1 \%)$ & $65(81.7 \%)$ & $287(89.7 \%)$ \\
\hline ER and PgR negative & $48(11.9 \%)$ & $15(18.3 \%)$ & $33(10.3 \%)$ \\
\hline \multicolumn{4}{|l|}{ HER2 status** } \\
\hline Positive & $49(12.2 \%)$ & $19(23.2 \%)$ & $30(9.3 \%)$ \\
\hline Negative & $344(85.6 \%)$ & $62(75.6 \%)$ & $282(88.2 \%)$ \\
\hline Unknown & $9(2.2 \%)$ & $1(1.2 \%)$ & $8(2.5 \%)$ \\
\hline \multicolumn{4}{|l|}{ pN status } \\
\hline $\mathrm{pNO}$ & 319 (79.4\%) & $67(81.7 \%)$ & $252(78.8 \%)$ \\
\hline pN1 (1-3) & $74(18.4 \%)$ & $12(14.6 \%)$ & $62(19.4 \%)$ \\
\hline pN2 (4-9) & $6(1.5 \%)$ & $2(2.4 \%)$ & $4(1.3 \%)$ \\
\hline$\overline{p N 3}(\geq 10)$ & $3(0.7 \%)$ & $1(1.2 \%)$ & $2(0.6 \%)$ \\
\hline
\end{tabular}

* cut off: $10 \%$

** HER2 status positive if: IHC 3+; or IHC 2+ and amplified by FISH,SISH,CISH; or amplified by FISH,SISH,CISH.

these 49 patients (73.46\%): in 13/19 pT1a (68.4\%) and in 23/130 pT1b (76.6\%). Patient and tumour characteristics are reported in Table 9. Adjuvant chemotherapy was administered in $100 \%(19 / 19)$ of the younger patients (18-49 years) and in 100\% (6/6) of patients with metastatic lymph nodes, in $90 \%(18 / 20)$ of tumours with negative hormonal receptors, and $69.6 \%$ and $84.2 \%$ of G2 and G3 tumours, respectively.
We observed that 30 out of 36 patients treated with adjuvant chemotherapy were $\mathrm{pNO}$ and in these patients the choice of administered chemotherapy was independent of other patient and tumour characteristics and based only on HER2-positivity. An anthracycline-based regimen was administered in 34 of 36 HER2-positive patients (94.4\%) (anthracycline without taxane in $72.2 \%$ and anthracycline with taxane in 22.2\%); a CMF-like regimen in 1 patient 
Table 3 Patient and tumour characteristics of pT1a-pT1b tumours vs other stage I-II tumours in the NEMESI study

\begin{tabular}{|c|c|c|}
\hline & $\begin{array}{l}\text { Pathologica } \\
\text { excluded) }\end{array}$ & $\begin{array}{l}\text { bpT1a, } \\
\text { pT1b }\end{array}$ \\
\hline N. of patients & 1492 & 402 \\
\hline \multicolumn{3}{|c|}{ Distribution by age } \\
\hline $18-34$ & $23(1.5 \%)$ & $7(1.7 \%)$ \\
\hline $35-49$ & $384(25.7 \%)$ & $\begin{array}{l}85 \\
(21.1 \%)\end{array}$ \\
\hline $50-69$ & $754(50.5 \%)$ & $\begin{array}{l}230 \\
(57.2 \%)\end{array}$ \\
\hline$\geq 70$ & $331(22.2 \%)$ & $\begin{array}{l}80 \\
(19.9 \%)\end{array}$ \\
\hline \multicolumn{3}{|c|}{ Menopausal status } \\
\hline Pre- & $465(31.2 \%)$ & $\begin{array}{l}101 \\
(25.1 \%)\end{array}$ \\
\hline Post- & $1,014(68.0 \%)$ & $\begin{array}{l}293 \\
(72.8 \%)\end{array}$ \\
\hline Unknown & $13(0.9 \%)$ & $8(2.0 \%)$ \\
\hline \multicolumn{3}{|c|}{ Node sentinel biopsy } \\
\hline$\overline{Y e s}$ & $903(60.5 \%)$ & $\begin{array}{l}319 \\
(79.3 \%)\end{array}$ \\
\hline$\overline{\text { No }}$ & 589 (39.5\%) & $\begin{array}{l}83 \\
(20.7 \%)\end{array}$ \\
\hline $\begin{array}{l}\text { Axillary } \\
\text { dissection }\end{array}$ & & \\
\hline Yes & $941(63.1 \%)$ & $\begin{array}{l}137 \\
(34.1 \%) \\
\end{array}$ \\
\hline$\overline{\text { No }}$ & 551 (36.9\%) & $\begin{array}{l}265 \\
(65.9 \%)\end{array}$ \\
\hline \multicolumn{3}{|l|}{ Grading } \\
\hline$\overline{\mathrm{G} 1}$ & $120(8.0 \%)$ & $\begin{array}{l}101 \\
(25.1 \%)\end{array}$ \\
\hline$\overline{\mathrm{G} 2}$ & $741(48.7 \%)$ & $\begin{array}{l}221 \\
(55.0 \%)\end{array}$ \\
\hline$\overline{G 3}$ & 589 (39.5\%) & $\begin{array}{l}72 \\
(17.9 \%)\end{array}$ \\
\hline Unknown & $42(2.8 \%)$ & $8(2.0 \%)$ \\
\hline
\end{tabular}

\section{Proliferation index (Ki-}

67/MB1)

\begin{tabular}{lll}
\hline $0-18 \%$ & $707(47.4 \%)$ & $\begin{array}{l}283 \\
(70.6 \%)\end{array}$ \\
\hline $19-29 \%$ & $279(18.7 \%)$ & $\begin{array}{l}52 \\
(12.9 \%)\end{array}$ \\
\hline$\geq 30 \%$ & $461(30.9 \%)$ & 54 \\
& & $(13.4 \%)$ \\
\hline Unknown & $45(3.0 \%)$ & $13(3.2 \%)$ \\
\hline ER status & & 351 \\
\hline ER positive $(\geq 10 \%)$ & $1,215(81.4 \%)$ & $(87.3 \%)$ \\
\hline ER negative (0-9\%) & $276(18.5 \%)$ & 51 \\
& & $(12.7 \%)$ \\
\hline Unknown & $1(0.1 \%)$ & $0(0.0 \%)$ \\
\hline PgR status & & 300 \\
\hline PgR positive $(\geq 10 \%)$ & $1,038(69.6 \%)$ & $(74.6 \%)$ \\
\hline
\end{tabular}

Table 3 Patient and tumour characteristics of pT1a-pT1b tumours vs other stage I-II tumours in the NEMESI study (Continued)

\begin{tabular}{|c|c|c|}
\hline$\overline{\text { PgR negative (0-9\%) }}$ & $449(30.1 \%)$ & $\begin{array}{l}101 \\
(25.4 \%)\end{array}$ \\
\hline Unknown & $5(0.3 \%)$ & $0(0.0 \%)$ \\
\hline \multicolumn{3}{|l|}{ Hormonal status* } \\
\hline ER and/or PgR positive & $1,228(82.3 \%)$ & $\begin{array}{l}354 \\
(88.1 \%)\end{array}$ \\
\hline$\overline{E R}$ and $\mathrm{PgR}$ negative & $263(17.6 \%)$ & $\begin{array}{l}48 \\
(11.9 \%)\end{array}$ \\
\hline Unknown & $1(0.1 \%)$ & $0(0.0 \%)$ \\
\hline \multicolumn{3}{|l|}{ HER2 status** } \\
\hline$\overline{\text { Positive }}$ & $279(18.7 \%)$ & $\begin{array}{l}49 \\
(12.2 \%)\end{array}$ \\
\hline Negative & 1,185 (79.4\%) & $\begin{array}{l}344 \\
(85.6 \%)\end{array}$ \\
\hline Missing & $28(1.9 \%)$ & $9(2.2 \%)$ \\
\hline \multicolumn{3}{|l|}{ pN status } \\
\hline$\overline{\mathrm{pNO}}$ & 836 (56.0\%) & $\begin{array}{l}319 \\
(79.4 \%)\end{array}$ \\
\hline$\overline{p N 1}(1-3)$ & 477 (32.0\%) & $\begin{array}{l}74 \\
(18.4 \%)\end{array}$ \\
\hline$\overline{p N 2 ~(4-9) ~}$ & $113(7.6 \%)$ & $6(1.5 \%)$ \\
\hline$\overline{\mathrm{pN} 3}(\geq 10)$ & 66 (4.4\%) & $3(0.7 \%)$ \\
\hline
\end{tabular}

(2.7\%) and taxane without anthracycline in 1 patient $(2.7 \%)$. In 30 out of 36 patients treated with chemotherapy, also adjuvant trastuzumab was administered. Trastuzumab was delivered in all six patients with lymph node involvement and in 24 patients with pN0 disease (Table 9).

\section{Discussion}

In the NEMESI study, a retrospective study which enrolled 1,894 pathological stage I-II breast cancers, 402 pT1a-pT1b tumours were included. A multivariate analysis conducted to evaluate the influence of patient and tumour characteristics on the decision to administer or not adjuvant chemotherapy in pT1apT1b breast cancers, showed that younger age, grading G3, high proliferative index, ER-negative status and HER2-positive status were significantly associated with the decision to administer adjuvant chemotherapy. In the patients treated with adjuvant chemotherapy, an anthracycline-based regimen was administered in $83.5 \%$ (anthracycline without taxane in $59.1 \%$ and anthracycline with taxane in $24.4 \%$ ) while a CMF-like regimen was administered in only $13.38 \%$. In our study compliance to adjuvant chemotherapy was high $(82.67 \%$ of patients received $4-6$ planned cycles) and the definitive interruption of chemotherapy occurred in only eight patients. 
Table 4 Adjuvant chemotherapy and patient/tumour characteristics

\begin{tabular}{lll}
\hline & $\begin{array}{l}\text { pT1a, pT1b } \\
\text { total patients } \\
\text { (N= 402) }\end{array}$ & $\begin{array}{l}\text { Patients treated with } \\
\text { adjuvant chemotherapy } \\
\text { (N= 127)* }\end{array}$ \\
\hline Distribution by age & & \\
\hline $18-34$ & $7 / 402(1.7 \%)$ & $6 / 7(85.7 \%)$ \\
\hline $35-49$ & $85 / 402(21.1 \%)$ & $46 / 85(54.1 \%)$ \\
\hline $50-69$ & $230 / 402(57.2 \%)$ & $67 / 230(29.1 \%)$ \\
\hline$\geq 70$ & $80 / 402(19.9 \%)$ & $8 / 80(10.0 \%)$ \\
\hline Menopausal status & & \\
\hline Pre- & $101 / 402(25.1 \%)$ & $52 / 101(51.5 \%)$ \\
\hline Post- & $293 / 402(72.8 \%)$ & $72 / 293(24.6 \%)$ \\
\hline Unknown & $8 / 402(2.0 \%)$ & $3 / 8(37.5 \%)$ \\
\hline Grading & & \\
\hline G1 & $101 / 402(25.1 \%)$ & $9 / 101(8.9 \%)$ \\
\hline G2 & $221 / 402(55.0 \%)$ & $66 / 221(29.8 \%)$ \\
\hline G3 & $72 / 402(17.9 \%)$ & $49 / 72(68.0 \%)$ \\
\hline Unknown & $8 / 402(2.0 \%)$ & $3 / 8(37.5 \%)$ \\
\hline Proliferation index (Ki-67/MB1) & \\
\hline O-18\% & $283 / 402(70.6 \%)$ & $55 / 283(19.4 \%)$ \\
\hline 19-29\% & $52 / 402(12.9 \%)$ & $28 / 53(52.8 \%)$ \\
\hline$\geq 30 \%$ & $54 / 402(13.4 \%)$ & $41 / 54(75.9 \%)$ \\
\hline Unknown & $13 / 402(3.2 \%)$ & $3 / 13(23.0 \%)$ \\
\hline ER status & \\
\hline
\end{tabular}

\section{ER status}

\begin{tabular}{lll}
\hline ER positive $(\geq 10 \%)$ & $351 / 402(87.3 \%)$ & $82 / 351(23.6 \%)$ \\
\hline ER negative (0-9\%) & $51 / 402(12.7 \%)$ & $45 / 51(88.2 \%)$ \\
\hline Hormonal status* & & \\
\hline ER and/or PgR positive & $354 / 402(74.6 \%)$ & $84 / 354(24.0 \%)$ \\
\hline ER and PgR negative & $48 / 402(25.4 \%)$ & $43 / 48(89.6 \%)$ \\
\hline HER2 status** & & \\
\hline Positive & $49 / 402(12.2 \%)$ & $36 / 49(73.5 \%)$ \\
\hline Negative & $344 / 402(85.6 \%)$ & $90 / 344(26.2 \%)$ \\
\hline Missing & $9 / 402(2.2 \%)$ & $1 / 9(11.1 \%)$ \\
\hline pN status & & \\
\hline pN0 & $319 / 402(79.4 \%)$ & $72 / 319(22.6 \%)$ \\
\hline pN1 (1-3) & $74 / 402(18.4 \%)$ & $47 / 74(63.5 \%)$ \\
\hline pN2 (4-9) & $6 / 402(1.5 \%)$ & $5 / 6(83.3 \%)$ \\
\hline pN3 ( $\geq 10)$ & $3 / 402(0.7 \%)$ & $3 / 3(100 \%)$ \\
\hline
\end{tabular}

* cut off: $10 \%$.

** HER2 status positive if: IHC $3+$; or IHC $2+$ and amplified by $\mathrm{FISH}, \mathrm{SISH}, \mathrm{CISH}$; or amplified by FISH,SISH,CISH.

The adjuvant systemic therapy of small tumour size with no axillary lymph node involvement is controversial. The risk of relapse is related to stage of tumour (tumour size and lymph node status) and to biological characteristics. Therefore, in pT1a-pT1b tumours, which are pN0 in $82 \%-85 \%$ of the cases, the biological markers are utilised during treatment decision-making. In our study, the variables significantly associated with the decision to administer adjuvant chemotherapy in pT1a-pT1b breast
Table 5 Results of the multivariate logistic model analysis evaluating the probability of being treated with adjuvant chemotherapy for pT1a and pT1b breast cancers

\begin{tabular}{llll}
\hline Variable & Odds ratio & $\mathbf{9 5 \%} \mathbf{C l}$ & P value \\
\hline Age range (years) & & & 0.0185 \\
\hline$\geq 70$ & 1 & $\mathrm{NE}$ & \\
\hline $18-34$ & $\mathrm{NE}$ & $2.00-33.67$ & \\
\hline $35-49$ & 8.22 & $0.69-8.58$ & \\
\hline $50-70$ & 2.44 & & 0.024 \\
\hline Grading & & & \\
\hline G1 & 1 & $0.56-5.01$ & \\
\hline G2 & 3.48 & $1.82-33$ & \\
\hline G3 & 8.33 & & 0.0007 \\
\hline ER receptor & & & \\
\hline Positive & 1 & $2.78-47.03$ & \\
\hline Negative & 11.43 & & \\
\hline Proliferative index & & & \\
\hline Low & 1 & 0.001 \\
\hline Medium & 2.08 & $2.57-33$ & \\
\hline High & 9.10 & & \\
\hline HER2 & & & \\
\hline Negative & $9.73-33.3$ & \\
\hline Positive & & & \\
\hline NE, not evar & & & \\
\hline
\end{tabular}

$\mathrm{NE}$, not evaluable due to the small sample in this category.

cancers were younger age and the biological markers associated with a poor prognosis (grading G3, high proliferative index, ER-negative status and HER2-positive status) [14,16,21-28], and also predictive of chemoresponsivity in the neoadjuvant setting.

Several changes in indication to adjuvant systemic therapy occurred for patients with node-negative tumours $\leq$ $1 \mathrm{~cm}$ in size according to 1998-2007 St Gallen Consensus Conference guidelines. In the 1998 St Gallen Consensus Conference the population with $<10 \%$ of relapse was not

Table 6 Results of the multivariate logistic model analysis evaluating the probability of being treated with adjuvant chemotherapy for pT1b breast cancers

\begin{tabular}{llll}
\hline Variable & Odds ratio & $\mathbf{9 5 \%} \mathrm{Cl}$ & P value \\
\hline ER receptor & & & 0.001 \\
\hline Positive & 1 & & \\
\hline Negative & 21.30 & $3.40-133.28$ & \\
\hline Proliferative index & & & $<0.0001$ \\
\hline Low & 1 & & \\
\hline Medium & 15 & $0.86-21.31$ & \\
\hline High & 20 & $5.56-100$ & \\
\hline HER2 & & & \\
\hline Negative & 1 & & \\
\hline Positive & 20 & $4.35-100$ & \\
\hline
\end{tabular}


Table 7 Type of chemotherapy administered in 127 patients with pT1a, pT1b breast cancers

\begin{tabular}{llll}
\hline & $\begin{array}{l}\text { All pts } \\
(\mathbf{N}=127)\end{array}$ & $\begin{array}{l}\text { pT1a pts } \\
(=27)\end{array}$ & $\begin{array}{l}\text { pT1b pts } \\
(\mathbf{N}=100)\end{array}$ \\
\hline Regimen & & & \\
\hline CMF-like & $18 / 127(14.2 \%)$ & $3 / 27(11.1 \%)$ & $15 / 100(15 \%)$ \\
\hline $\begin{array}{l}\text { Anthracycline } \\
\text { without taxane }\end{array}$ & $75 / 127(59.1 \%)$ & $21 / 27(77.8 \%)$ & $54 / 100(54 \%)$ \\
\hline $\begin{array}{l}\text { Anthracycline } \\
\text { with taxane }\end{array}$ & $31 / 127(24.4 \%)$ & $3 / 27(11.1 \%)$ & $28 / 100(28 \%)$ \\
\hline $\begin{array}{l}\text { Taxane } \\
\text { without anthracycline }\end{array}$ & $3 / 127(2.4 \%)$ & 0 & $3 / 100(3 \%)$ \\
\hline
\end{tabular}

considered for adjuvant systemic therapy [29]. The 2005 Consensus Conference made a fundamental change in the algorithm for the selection of adjuvant systemic therapy for early breast cancer, considering first endocrine responsiveness and then the risk of relapse. The risk allocation of tumours below $1 \mathrm{~cm}$ in size and negative nodes remained still controversial [30]. The $2007 \mathrm{St}$ Gallen Consensus Conference [31] utilised the biological factors associated to worse prognosis, considered singularly or together, to identify the endocrine non responsive tumours suitable for only adjuvant chemotherapy, and to identify the incompletely or highly endocrine responsive tumours suitable,
Table 8 Type of hormonal therapy administered according to menopausal status in 346 pT1a and pT1b tumours

\begin{tabular}{lll}
\hline & $\begin{array}{l}\text { Premenopausal } \\
(\mathbf{N}=\mathbf{8 9})\end{array}$ & $\begin{array}{l}\text { Postmenopausal } \\
\mathbf{( N = 2 5 7 )}\end{array}$ \\
\hline Hormonal therapy & $11(12.3 \%)$ & $35(13.6 \%)$ \\
\hline Tamoxifen $5 \mathrm{y}$ & $65(73.0 \%)$ & $0(0.0 \%)$ \\
\hline $\begin{array}{l}\text { Tamoxifen } \\
5 \mathrm{y}+\text { LHRH }\end{array}$ & $3(3.3 \%)$ & $44(17.1 \%)$ \\
\hline $\begin{array}{l}\text { Tamoxifen } \\
2-3 y \rightarrow \text { Aromatase } \\
\text { Inhibitor 3-2 y }\end{array}$ & & \\
\hline $\begin{array}{l}\text { Aromatase } \\
\text { Inhibitor } 5 \mathrm{y}\end{array}$ & $1(1.1 \%)$ & $173(67.3 \%)$ \\
\hline $\begin{array}{l}\text { Aromatase Inhibitor } \\
5 \mathrm{y}+\text { LHRH }\end{array}$ & $6(6.7 \%)$ & $1(0.4 \%)$ \\
\hline LHRH alone & $1(1.1 \%)$ & $0(0.0 \%)$ \\
\hline Other & $2(2.2 \%)$ & $4(1.6 \%)$ \\
\hline
\end{tabular}

according to risk of relapse, for addition of adjuvant chemotherapy to hormonal therapy, irrespective of tumour size. However, some but not all panel members viewed $\mathrm{pT} \leq 1 \mathrm{~cm}$ tumours with node-negative disease as representing low risk even if higher grade and/or younger age. The NCCN Practice Guidelines 2007 [www.nccn.org]

Table 9 Adjuvant chemotherapy and adjuvant trastuzumab by tumour and patient characteristics in HER2-positive pT1a and pT1b breast cancers $(n=49)$

\begin{tabular}{|c|c|c|c|}
\hline & $\begin{array}{l}\text { All HER2-positive } \\
\text { tumours }\end{array}$ & $\begin{array}{l}\text { HER2-positive tumours } \\
\text { treated with adjuvant } \\
\text { chemotherapy* }\end{array}$ & $\begin{array}{l}\text { HER2-positive tumours treated } \\
\text { with adjuvant chemotherapy } \\
\text { and trastuzumab * }\end{array}$ \\
\hline No. of patients & 49 & 36 (73.5\%) & $30(61.2 \%)$ \\
\hline \multicolumn{4}{|c|}{ Menopausal status } \\
\hline pre- & 19 & $18(94.7 \%)$ & $14(73.7 \%)$ \\
\hline post- & 30 & $18(60.0 \%)$ & $16(53.3 \%)$ \\
\hline \multicolumn{4}{|l|}{ Age (years) } \\
\hline $18-34$ & 2 & $2(100.0 \%)$ & $2(100.0 \%)$ \\
\hline $35-49$ & 17 & $17(100.0 \%)$ & $12(70.6 \%)$ \\
\hline $50-69$ & 25 & $16(64.0 \%)$ & $15(60.0 \%)$ \\
\hline$\geq 70$ & 5 & $1(20.0 \%)$ & $1(20.0 \%)$ \\
\hline \multicolumn{4}{|c|}{ Hormonal receptor status } \\
\hline positive & 29 & $18(62.1 \%)$ & $15(51.7 \%)$ \\
\hline negative & 20 & $18(90.0 \%)$ & $15(75.0 \%)$ \\
\hline \multicolumn{4}{|l|}{ LN status } \\
\hline $\mathrm{pNO}$ & 43 & $30(69.7 \%)$ & $24(55.8 \%)$ \\
\hline $\mathrm{pN1}$ & 4 & $4(100.0 \%)$ & $4(100.0 \%)$ \\
\hline $\mathrm{pN2}$ & 2 & $2(100.0 \%)$ & $2(100.0 \%)$ \\
\hline \multicolumn{4}{|l|}{ Grading } \\
\hline G1 & 2 & $1(50.0 \%)$ & $0(0.0 \%)$ \\
\hline $\mathrm{G} 2$ & 23 & $16(69.6 \%)$ & $13(56.5 \%)$ \\
\hline G3 & 19 & $16(84.2 \%)$ & $16(84.2 \%)$ \\
\hline
\end{tabular}

\footnotetext{
* Values and percentages are based on the all HER2-positive patients
} 
recommended adjuvant chemotherapy only in tumours between $6 \mathrm{~mm}$ and $10 \mathrm{~mm}$ without metastases in lymph nodes (pT1b pN0): in ER-negative pT1b pN0 (both HER2negative and HER2-positive) and, in addition to hormonal therapy, in ER positive pT1b pN0 moderate/poorly differentiated or with unfavourable features (both HER2-negative and HER2-positive).

We report that an anthracycline-based regimen was administered in $83.5 \%$ of patients (anthracycline without taxane in 59.1\% and anthracycline with taxane in $24.4 \%$ ) while CMF-like anthracycline-regimens (without or with taxane) highlights that if the decision was to administer chemotherapy, the most active regimen was selected, also in small breast cancers. This trend was observed also in all patients with stage I-II breast cancer enrolled in the NEMESI study [32] as well as in the NEMESI subgroup of triple-negative tumours [33].

Our study has some limits. Although the majority of pT1a-pT1b breast cancers had favourable prognostic factors, as reported in other retrospective studies [7-11], adjuvant chemotherapy was delivered in $31.59 \%$ of patients. This percentage is considerable but may not reflect the clinical practice and must be evaluated considering both the eligibility criteria of NEMESI (the patients enrolled must have received at least one cycle of adjuvant chemotherapy and/or adjuvant hormonal therapy) and the requirement that each centre had to collect the data of at least $33 \%$ of the patients undergoing adjuvant chemotherapy. It is necessary consider this limit also when we reported that 36 out of 49 patients with HER2-positive small breast cancer were treated with adjuvant chemotherapy (73.46\%). Thirty out of these 36 HER2-positive patients were pN0 and in these patients the choice of administered chemotherapy was independent of other patient and tumour characteristics and based only on HER2positivity, considered a poor prognostic factor [22-24], as well confirmed by recent studies [25-28]. Adjuvant trastuzumab was administered in 30 of 36 patients who received chemotherapy. HER2-positivity is a predictive factor of trastuzumab response, but although five out of six randomised phase III trials reported marked benefit of adjuvant trastuzumab for disease-free and overall survival (with reduction of recurrence and mortality by 20-40\%) [34-38], there are no data on trastuzumab in pT1a-pT1b HER2positive breast cancer. On the other hand, there is indirect evidence. In the BCIRG006 and HERA subgroup analyses adjuvant trastuzumab did not result in different rates of risk reduction among HER2-positive breast cancers in function of nodal status or tumour size $[35,39,40]$. More data supporting the use of adjuvant trastuzumab in small node-negative HER2-positive breast cancer emerged from three recently reported retrospective investigations. In a French multicenter series from 2002 to 2008, 97 patients with pT1a,b pN0 HER2-positive tumours were identified.
Forty-one patients (42\%) had been treated with adjuvant trastuzumab-based therapy with $(n=38)$ or without $(n=3)$ chemotherapy [41]. The decision to administer adjuvant trastuzumab was significantly associated with a negative hormonal receptor status, a high Eltson-Ellis grade, a moderate/high mitotic index, and the date of the diagnosis (before or after the HERA results were released). With a median follow-up of 29 months, there were no recurrences in patients treated with trastuzumab-based therapy while 5 of 56 patients who did not receive trastuzumab had developed a recurrence. Another single-institution retrospective study included 485 women with node-negative, HER2-positive tumours $\leq 2 \mathrm{~cm}$ treated in the pre- (20022004) and post- (2005-2008) trastuzumab era [42]. Events of disease recurrence were more frequent in the pre-trastuzumab group as compared with the post-trastuzumab group. A third study reported the breast cancer specific 5year survival of HER2-positive pT1a and pT1b pN0 breast cancer in 20,188 patients identified in the California Cancer Registry [43]. It was significantly shorter among HER2positive breast cancer compared to HER2-negative patients $(\mathrm{p}=0.0001)$ in the 2000-2004 era, while there was no difference in the 2005-2007 era, after the introduction in clinical practice of adjuvant trastuzumab.

The 2007 St Gallen Consensus Conference did not recommend adjuvant trastuzumab in women with a primary tumour $<1 \mathrm{~cm}$ in size and with no axillary node involvement [31], and also the 2007 NCCN Guidelines did not indicate trastuzumab in tumours $<1 \mathrm{~cm}$. On the other hand, the more recent version of the NCCN Guidelines 2011 (v.2.2011) recommend the use of adjuvant trastuzumab in women with node-negative tumours (both HR-positive and HR-negative) that are 0.6 to $1.0 \mathrm{~cm}$ as category 2A recommendation, because patients with tumours $1 \mathrm{~cm}$ or smaller and node negative were not consistently included in the available clinical trials. The majority of the Panel members of the 2011 St Gallen Consensus Conference were willing to extended adjuvant trastuzumab to patients with pT1b, but not pT1a pN0 disease [44].

Moreover, hormonal therapy, planned in 351 patients out of 354 hormonal receptor-positive pT1a-pT1b tumours, was administered in 346 patients (97.7\%). These data are very different from those reported by an audit of clinical practice in Italy conducted in March 2000 regarding adjuvant systemic therapies prescribed for breast cancer. In this audit it resulted that endocrine therapy was not prescribed in 102 out of 541 patients (19\%) with endocrine-responsive disease [45].

\section{Conclusions}

In conclusion, the choice to deliver adjuvant chemotherapy to patients with pT1a-pT1b breast cancer treated at 63 Italian oncological centres from January 2008 to June 2008 was based on tumour biology. When it was decided to 
administer adjuvant chemotherapy, the most active regimens, anthracycline-based, were selected. Compliance to treatment was excellent.

\section{Competing interests}

The authors declare that they have no competing interests except for $D$. Dondi who is an employee of Sanofi-Aventis.

\section{Acknowledgements}

The NEMESI study was funded by Sanofi-Aventis. The sponsor did not interfere in any way in the interpretation of data or in the content of the manuscript.

\section{Author details}

'Oncologia Medica, Ospedale Santa Maria della Misericordia, Azienda Ospedaliera di Perugia, Perugia Italy. ${ }^{2}$ Oncologia, Ospedale Sacro Cuore-Don Calabria, Negrar (VR), Italy. ${ }^{3}$ Struttura Complessa di Oncologia Falck, Ospedale Niguarda Ca' Granda, Milan Italy. ${ }^{4} \cup O$ Oncologia, Azienda Ospedaliera Sant'Anna, Como Italy. ${ }^{5}$ U.O.C. di Oncologia dell'Ospedale Civile Maggiore, Azienda Ospedaliera-Universitaria di Verona, Verona Italy. ${ }^{6}$ Oncologia Medica, Ospedale di Bolzano, Bolzano Italy. ${ }^{7}$ Oncologia, Azienda Ospedaliera di Alessandria, Alessandria Italy. ${ }^{8} \mathrm{SC}$ Oncologia, Azienda OspedalieroUniversitaria "Maggiore della Carità", Novara Italy. ${ }^{9}$ Oncologia Medica, Ospedale Campo di Marte, Lucca Italy. ${ }^{10}$ UO Oncologia Medica, Ospedale S.S. Trinità, Sora (FR), Sassari Italy. ${ }^{11}$ Oncologia Medica, Università degli Studi Messina, Messina Italy. ${ }^{12}$ Medical \& Scientific Department, Sanofi-Aventis, Milan Italy. ${ }^{13}$ Division of Medical Oncology, Ospedale S. Maria della Misericordia, Azienda Ospedaliera Perugia, via Dottori 1, Perugia 06122, Italy.

\section{Authors' contribution}

All authors have contributed to the conception and design of the study, acquisition and interpretation of data. Stefania Gori was responsible for drafting the manuscript. All authors have given approval to this version of the manuscript.

\section{Received: 7 July 2011 Accepted: 30 April 2012}

Published: 30 April 2012

\section{References}

1. Grande E, Inghelmann R, Francisci S, Verdecchia A, Micheli A, Baili P, Capocaccia R, De Angelis R: Regional estimates of breast cancer burden in Italy. Tumori 2007, 93(4):374-379.

2. Botha JL, Bray F, Sankila R, Parkin DM: Breast cancer incidence and mortality trends in 16 European countries. Eur J Cancer 2003, 39 (12):1718-1729.

3. Glass AG, Lacey JV Jr, Carreon JD, Hoover RN: Breast cancer incidence, 1980-2006: combined roles of menopausal hormone therapy, screening mammography, and estrogen receptor status. J Natl Cancer Inst 2007, 99:1152-1161.

4. Ferlay J, Parkin DM, Steliarova-Foucher E: Estimates of cancer incidence and mortality in Europe in 2008. Eur J Cancer 2010, 46:765-781.

5. Vacek PM, Geller BM, Weaver DL, Foster RS Jr: Increased mammography use and its impact on earlier breast cancer detection in Vermont, 1975-1999. Cancer 2002, 94:2160-2168.

6. Fracheboud J, Otto SJ, van Dijck JA, Broeders MJ, Verbeek AL, De Koning HJ, National Evaluation Team for Breast cancer screening (NETB): Decreased rates of advanced breast cancer due to mammography screening in The Netherlands. Br J Cancer 2004, 91:861-867.

7. Rosen PP, Groshen S, Kinne DW, Norton L: Factors influencing prognosis in node-negative breast carcinoma: analysis of 767 T1NOMO/T2NOMO patients with long-term follow-up. J Clin Oncol 1993, 11:2090-2100

8. Leitner SP, Swern AS, Weinberger D, Duncan $\sqcup$, Hutter RV: Predictors of recurrence for patients with small (one centimeter or less) localized breast cancer (T1a, b NO, MO). Cancer 1995, 76:2266-2274.

9. Arnesson LG, Smeds S, Fagerberg G: Recurrence-free survival in patients with small breast cancer. An analysis of cancers $10 \mathrm{~mm}$ or less detected clinically and by screening. Eur J Surg 1994, 160:271-276.

10. Lee AK, Loda M, Mackarem G, Bosari S, DeLellis RA, Heatley GJ, Hughes K: Lymph node negative invasive breast carcinoma 1 centimeter or less in size (T1a, b N0 M0): clinicopathologic features and outcome. Cancer 1997, 79:761-771.

11. Tinnemans JG, Wobbes T, Holland R, Hendriks JH, Van der Sluis RF, De Boer HH: Treatment and survival of female patients with nonpalpable breast carcinoma. Ann Surg 1989, 209:249-253.

12. Crowe JP Jr, Gordon NH, Shenk RR, Zollinger RM Jr, Brumberg DJ, Shuck JM: Primary tumour size. Relevance to breast cancer survival. Arch Surg 1992. 127:910-915.

13. Moon TE, Jones SE, Bonadonna G, Valagussa P, Powles T, Buzdar A, Montague $E$ : Development and use of a natural history data base of breast cancer studies. Am J Clin Oncol 1987, 10:396-403.

14. Chia SK, Speers CH, Bryce CJ, Hayes MM, Olivotto IA: Ten-year outcomes in a population-based cohort of node-negative, lymphatic, and vascular invasion-negative early breast cancers without adjuvant systemic therapies. J Clin Oncol 2004, 22:1630-1637.

15. Quiet CA, Ferguson DJ, Weichselbaum RR, Hellman S: Natural history of node-negative breast cancer: a study of 826 patients with long-term follow-up. J Clin Oncol 1995, 13:1144-1151.

16. Fisher B, Dignam J, Tan-Chiu E, Anderson S, Fisher ER, Wittliff JL, Wolmark N: Prognosis and treatment of patients with breast tumors of one centimetre or less and negative axillary lymph nodes. J Natl Cancer Inst 2001, 93:112-120.

17. Associazione Italiana di Oncologia Medica (AIOM): Libro bianco. 3 rd edition. Italy; 2006.

18. Singletary SE, Allred C, Ashley P, Bassett LW, Berry D, Bland KI, Borgen PI, Clark G, Edge SB, Hayes DF, Hughes LL, Hutter RV, Morrow M, Page DL, Recht A, Theriault RL, Thor A, Weaver DL, Wieand HS, Greene FL: Revision of the American joint committee on cancer staging system for breast cancer. J Clin Oncol 2002, 20:3628-3636.

19. Agenzia Italiana del Farmaco (AIFA): Linee guida per la classificazione e la conduzione di studi osservazionali su farmaci. In. Italy; Gazzetta Ufficiale. Serie ufficiale 76; 30/03/2008.

20. World Medical Organization: Declaration of Helsinki (1964). BMJ 1996 , 313:1448a-1449a.

21. Colleoni M, Rotmensz N, Peruzzotti G, Maisonneuve P, Viale G, Renne G, Casadio C, Veronesi P, Intra M, Torrisi R, Goldhirsch A: Minimal and small size invasive breast cancer with no axillary lymph node involvement: the need for tailored adjuvant therapies. Ann Oncol 2004, 15:1633-1639.

22. Joensuu H, Isola J, Lundin M, Salminen T, Holli K, Kataja V, Pylkkänen L, Turpeenniemi-Hujanen T, von Smitten K, Lundin J: Amplification of erbB2 and erbB2 expression are superior to estrogen receptor status as risk factors for distant recurrence in PT1NOMO breast cancer: a nationwide population based study. Clin Cancer Res 2003, 9:923-930.

23. Black $D$, Younger J, Martei $Y$, et al: Recurrence risk in T1a.-b, nodenegative, HER positive breast cancer. Breast Cancer Res Treat 2006, 100 (suppl 1):abstract 2037.

24. Chia S, Norris B, Speers C, Cheang M, Gilks B, Gown AM, Huntsman D, Olivotto IA, Nielsen TO, Gelmon K: Human epidermal growth factor receptor 2 overexpression as a prognostic factor and a large tissue microarray series of node-negative breast cancers. J Clin Oncol 2008, 26:5697-5704.

25. Gonzalez-Angulo AM, Litton JK, Broglio KR, Meric-Bernstam F, Rakkhit $R$, Cardoso F, Peintinger F, Hanrahan EO, Sahin A, Guray M, Larsimont D, Feoli F, Stranzl H, Buchholz TA, Valero V, Theriault R, Piccart-Gebhart M, Ravdin PM, Berry DA, Hortobagyi GN: High risk of recurrence for patients with breast cancer who have human epidermal growth factor receptor 2-positive, node-negative tumors $1 \mathrm{~cm}$ or smaller. J Clin Oncol 2009, 27:5700-5706

26. Curigliano G, Viale G, Bagnardi V, Fumagalli L, Locatelli M, Rotmensz N, Ghisini R, Colleoni M, Munzone E, Veronesi P, Zurrida S, Nolè F, Goldhirsch A: Clinical relevance of HER2 overexpression/amplification in patients with small tumor size and node-negative breast cancer. J Clin Oncol 2009, 27:5693-5699.

27. Tovey SM, Brown S, Doughty JC, Mallon EA, Cooke TG, Edwards J: Poor survival outcomes in HER2-positive breast cancer patients with low-grade, node-negative tumours. Br J Cancer 2009, 100:680-683.

28. Amar S, McCullough AE, Tan W, Geiger XJ, Boughey JC, McNeil RB, Coppola $K E$, McLaughlin SA, Palmieri FM, Perez EA: Prognosis and outcome of small $(<=1 \mathrm{~cm})$, node-negative breast cancer on the basis of hormonal and HER-2 status. Oncologist 2010, 15:1043-1049.

29. Goldhirsch A, Glick JH, Gelber RD, Senn HJ: Meeting highlights: international consensus panel on the treatment of primary breast cancer. J Natl Cancer Inst 1998, 90:1601-1608. 
30. Goldhirsch A, Glick JH, Gelber RD, Coates AS, Thurlimann B, Senn HJ: Meeting highlights: international expert consensus on the primary therapy of early breast cancer 2005. Ann Oncol 2005, 16:1569-1583.

31. Goldhirsch A, Wood WC, Gelber RD, Coates AS, Thurlimann B, Senn HJ: Progress and promise: highlights of the international expert consensus on the primary therapy of early breast cancer. Ann Oncol 2007, 2007:181133-181144.

32. Mustacchi G, Cazzaniga ME, Pronzato $P$, et al: Adjuvant chemotherapy for early breast cancer in Italy: what has changed today versus the early 2000 's. A comparison between two observational national studies. NORA and NEMESI. Ann Oncol 2010, 21(suppl 8):abstract 233P.

33. Adamo V, Ricciardi GRR, De Placido S, Colucci G, Conte P, Giuffrida D, Gebbia N, Masci G, Cognetti F, Dondi D, Venturini M: Management and treatment of triple-negative breast cancer patients from NEMESI study: an Italian experience. Eur J Oncol 2011. doi:10.1016/ejca.2011.06.028.

34. Piccart-Gebhart MJ, Procter M, Leyland-Jones B, Goldhirsch A, Untch M, Smith I, Gianni L, Baselga J, Bell R, Jackisch C, Cameron D, Dowsett M, Barrios CH, Steger G, Huang CS, Andersson M, Inbar M, Lichinitser M, Láng I, Nitz U, Iwata H, Thomssen C, Lohrisch C, Suter TM, Rüschoff J, Suto T, Greatorex V, Ward C, Straehle C, McFadden E, Dolci MS, Gelber RD, Herceptin Adjuvant (HERA) Trial Study Team: Trastuzumab after adjuvant chemotherapy in HER2-positive breast cancer. N Engl J Med 2005, 353:1659-1672.

35. Slamon D, Eiermann W, Robert N, et al: 2nd interim analysis phase III randomized trial comparing doxorubicin and cyclophosphamide followed by docetaxel $(\mathrm{AC} \rightarrow \mathrm{T})$ with doxorubicin and cyclophosphamide followed by docetaxel and trastuzumab $(\mathrm{AC} \rightarrow \mathrm{TH})$ with docetaxel, carboplatin and trastuzumab (TCH) in HER2/neu positive early breast cancer patients. Breast Cancer Res Treat 2006, 100:abstract 52.

36. Romond EH, Perez EA, Bryant J, Suman VJ, Geyer CE Jr, Davidson NE, Tan-Chiu E, Martino S, Paik S, Kaufman PA, Swain SM, Pisansky TM, Fehrenbacher L, Kutteh LA, Vogel VG, Visscher DW, Yothers G, Jenkins RB, Brown AM, Dakhil SR, Mamounas EP, Lingle WL, Klein PM, Ingle JN, Wolmark N: Trastuzumab with adjuvant chemotherapy for operable HER2-positive breast cancer. N Engl J Med 2005, 353:1673-1684.

37. Spielmann M, Roché $H$, Delozier $T$, Canon $J$, Romieu G, Bourgeois $H$, Extra JM, Serin D, Kerbrat P, Machiels JP, Lortholary A, Orfeuvre H, Campone M, Hardy-Bessard AC, Coudert B, Maerevoet M, Piot G, Kramar A, Martin AL, Penault-Llorca F: Trastuzumab for patients with axillary node positive breast cancer: results of the FNCLCC-PACS 04 trial. J Clin Oncol 2009, 27:6129-6134

38. Joensuu H, Bono P, Kataja V, Alanko T, Kokko R, Asola R, Utriainen T, Turpeenniemi-Hujanen T, Jyrkkiö S, Möykkynen K, Helle L, Ingalsuo S, Pajunen M, Huusko M, Salminen T, Auvinen P, Leinonen $H$, Leinonen $M$, Isola J, Kellokumpu-Lehtinen PL: Fluorouracil, epirubicin, and cyclophosphamide with either docetaxel or vinorelbine, with or without trastuzumab, as adjuvant treatments of breast cancer: final results of the FinHer trial. J Clin Oncol 2009, 27:5685-5692.

39. Smith I, Procter M, Gelber RD, Guillaume S, Feyereislova A, Dowsett M, Goldhirsch A, Untch M, Mariani G, Baselga J, Kaufmann M, Cameron D, Bell R, Bergh J, Coleman R, Wardley A, Harbeck N, Lopez Rl, Mallmann P, Gelmon K, Wilcken N, Wist E, Sánchez Rovira P, Piccart-Gebhart MJ, HERA study team: 2-year follow-up of trastuzumab after adjuvant chemotherapy in HER2positive breast cancer: a randomised controlled trial. Lancet 2007, 369:2936.

40. Untch M, Gelber RD, Jackisch C, Procter M, Baselga J, Bell R, Cameron D, Bari M, Smith I, Leyland-Jones B, de Azambuja E, Wermuth P, Khasanov R, FengYi F, Constantin C, Mayordomo Jl, Su CH, Yu SY, Lluch A, Senkus-Konefka E, Price C, Haslbauer F, Suarez Sahui T, Srimuninnimit V, Colleoni M, Coates AS, Piccart-Gebhart MJ, Goldhirsch A, HERA Study Team: Estimating the magnitude of trastuzumab effects within patient subgroups in the HERA trial. Ann Oncol 2008, 19:1090-1096.

41. Rodrigues MJ, Wassermann J, Albiges L, Brain E, Delaloge S, Stevens D, Guinebretière JM, Mathieu MC, Kirova Y, Guillot E, Vincent-Salomon A, Cottu $\mathrm{PH}$ : Trastuzumab treatment in T1ab, node-negative, human epidermal growth factor receptor 2-overexpressing breast carcinomas. $J$ Clin Oncol 2010, 28:e541-e542.

42. McArthur HL, Mahoney K, Morris PG, Patil S, Jacks LM, Howard J, Norton L, Hudis C: Use of adjuvant trastuzumab with chemotherapy in women with small, node-negative, HER2-positive breast cancers. J Clin Oncol 2010, 28(7s):abstr 615.
43. Chew HK, Brown M: Cause-specific and all-cause mortality of HER2-positive, node-negative, T1a and T1b breast cancers. J Clin Oncol 2010, 28(7s):abstr 583

44. Goldhirsch A, Wood WC, Coates AS, Gelber RD, Thurlimann B, Senn H-J, Panel members: Strategy for subtypes- dealing with the diversity of breast cancer: highlights of the St Gallen international expert consensus on the primary therapy of early breast cancer 2011. Ann Oncol 2011, 22:1736-1747.

45. Roila F, Ballatori E, Patoia L, Palazzo S, Veronesi A, Frassoldati A, Cetto G, Cinieri S, Goldhirsch A: Adjuvant systemic therapies in women with breast cancer: an audit of clinical practice in Italy. Ann Oncol 2003, 14:843-848.

\section{doi:10.1186/1471-2407-12-158}

Cite this article as: Gori et al:: Adjuvant chemotherapy of pT1a and pT1b breast carcinoma: results from the NEMESI study. BMC Cancer 2012 $12: 158$.

\section{Submit your next manuscript to BioMed Central and take full advantage of:}

- Convenient online submission

- Thorough peer review

- No space constraints or color figure charges

- Immediate publication on acceptance

- Inclusion in PubMed, CAS, Scopus and Google Scholar

- Research which is freely available for redistribution 